\title{
Recent work of the Conference of European Statisticians
}

Work Session on Statistics of the Hidden and Informal Activities (Geneva, 16-18 September 1991)

The purpose of the work session was to review progress made by countries and various international organizations in compiling statistics on the hidden and informal economy and to advise the Conference of European Statisticians on further work in this field. The work session recommended that further study be carried out along the following lines: (i) revision of international terminology on statistics of the hidden economy; (ii) inventory of practices used in ECE member countries; (iii) consideration of methodological issues in the collection and validation of primary statistics on the hidden economy; and, (iv) selection of experts of statistics on the hidden economy on which international guidelines are needed.

Joint Programme Review Eurostat, OECD, ECE (Luxembourg, 26-27 September 1991)

The consultation reviewed the coordination of international statistical work undertaken by the three institutions. The purpose was to enhance integration of international statistical cooperation into the worldwide system of statistics and to avoid duplication of effort. The consultation was organized by Eurostat. The next meeting is planned in Geneva, September 1992, and will be organized by the ECE secretariat. 